\title{
Heat Transfer Enhancement of Small Scale Heat Sinks Using Vibrating Pin Fin
}

\author{
${ }^{1}$ Suabsakul Gururatana and ${ }^{2}$ Xianchang Li \\ ${ }^{1}$ Department of Mechanical Engineering, \\ Faculty of Engineering at Si Racha, Kasetsart University Si Racha Campus, Chonburi, 20230, Thailand \\ ${ }^{2}$ Department of Mechanical Engineering, College of Engineering, Lamar University, Beaumont, TX, 77710, USA
}

Received 2013-01-29, Revised 2013-05-04; Accepted 2013-07-09

\begin{abstract}
Heat sinks are widely adopted in electronics cooling together with different technologies to enhance the cooling process. For the small electronics application, the small scale pin fins heat sinks are extensively used to dissipate heat in electronics devices. Due to the limit of space in the small devices, it is impossible to increase heat transfer area. In order to improve the heat transfer performance, the applying the forced vibration is one of challenging method. This study applies the vibration frequency between 50 to $1,000 \mathrm{~Hz}$ to pin fins heat sinks. The results of numerical simulation clearly show satisfied heat transfer augmentation. However, the Pressure drop significantly increases with frequency. This phenomenon affects the heat transfer enhancement performance that it increases with frequency until certain value then it drops rapidly. The results of this study can help designing heat sinks for electronics cooling by employing the concept of vibration.
\end{abstract}

Keywords: Pin Fin, Heat Sink, Vibration, Frequency, Small Scale

\section{INTRODUCTION}

The power density of microchip has been increasing along with the rapid development in electronic technology. Cooling of electronic systems is therefore essential in controlling the component temperature and avoiding any hot spot. Heat sinks are commonly adopted together with other technologies to enhance the heat transfer process. In general, heat sinks are designed to take advantage of extended surfaces--fins, either plate fins or pin fins. Jet impingement can also be incorporated into the design to further enhance the heat transfer.

The rapid development of engineering application for micro-devices, micro-manufacturing, micro-systems is creating demand for better understanding the micro scale phenomena. Nowadays, the micro-devices are widely used in electronic application especially for cooling the computer chip. Early work on the micro channel heat sink, it was examined by Tuckerman and Pease (1981). They showed a feasibility study to use force convection micro channel in electronic cooling. This heat sink had every low thermal resistance. The study also showed that the micro channel presented good heat dissipation rate from the electronic chips and this results guaranteed the potential of this technology.

While optimization of geometric and flow parameters can improve the heat sink performance, new fin designs are explored by different researchers. Takada et al. (1990) conducted an experimental study on a novel forced-convection air-cooled heat sink for high powerdensity computers. The perforated trapezoidal fin has been presented. The result showed that the heat transfer coefficient of proposed fins is approximately two times that of the parallel plate fin at the same velocity. Li and Wirtz (2005) experimentally measured the pressure drop and thermal performance of novel high-performance heat sinks based on screen-fin technology. The fin geometry was evaluated and the most suitable fin geometry was found. Ozturk and Tari (2008) examined different commercial heat sinks by Kasetsart University Si Racha Campus, Chonburi, 20230, Thailand 
using numerical simulation. The best heat sink has been selected and further improvement was made by replacing materials and redesigning the geometric configuration. Hui and Xin (2008) designed and developed a CPU fan with heat sink. The performance of the designed CPU fan with radial fins was studied. The results demonstrated that the thermal resistance of heat sink was decreased by $15 \%$ when compared with the traditional heat sink.

Flow over bluff body is important in many engineering application. Most researchers focused on the flow over cylinder and square. For the flow past the cylinder, the vortices are shed with natural frequency and vortex shedding can be controlled by oscillation of cylinder. It is referred to a vortex resonance phenomenon. This phenomenon is used to enhance wake to increase the heat transfer in electronics devices, fuel cell, heat exchanger and so on. Forbes et al. (1970) experimentally studied effect of vibration on natural convection in an enclosure of rectangular cross-section. The mechanical vibration was generated by electrodynamics vibrator and frequencies from 0 to 4,000 $\mathrm{Hz}$ were utilized in this study. This study mentioned that when the frequency was close to natural frequency of the column of fluid, the convection heat transfer was increased as high as $50 \%$.

$\mathrm{Fu}$ and Yang (2001a) observed the heat transfer phenomena induced by moving square object. The finite element method with Arbitrary Lagrangian-Eulerian (ALE) method was used to simulate the moving boundary problem. The results indicated that the heat transfer rate remarkably increased when object moved in opposition to flowing fluid. Fu and Yang (2001b) presented the new concept of cooling strategy, the swing fins. The study was conducted by finite element method with ALE. It could be seen that swing fins clearly disrupted the thermal and velocity boundary layers along the fin surface. Heat transfer would be improving when fins moved at large speed. However, when fins were swinging at low speed, the results were similar to the flow over flat plate without vibration. Fu et al. (2001) numerically investigated heat transfer rate from heat plate with jet impingement. The heat transfer performance was improved by implementing the moving block on the plate surface. After installing moving block, thermal boundary layer was eliminated and new thermal boundary layer was formed. These phenomena clearly improved the heat transfer performance. The results indicated that increment of heat transfer rate was approximately $200 \%$ at the highest Reynolds number. $\mathrm{Fu}$ and Tong (2002) used finite element method with ALE to study heat transfer characteristic from heated oscillating cylinder. The parameters such as Reynolds number, oscillating amplitude and oscillating speed were also considered. The consequence of vibration showed that vertex shedding was apparently produced behind the cylinder. Heat transfer was clearly enhanced when Reynolds number, oscillating amplitude and oscillating speed were increased.

Pottebaum and Gharib (2006) experimentally examined the flow over oscillating cylinder. The significant heat transfer enhancement was found when cylinder was oscillated by small amplitude at frequency near its natural frequency.

Ji et al. (2008) performed experiment to investigate heat transfer enhancement from heated cylinder in a channel by pulsating flow. They found that unsteady wake phenomenon was observed in the flow with pulsating. When the pulsating frequency was twice the natural shedding frequency, heat transfer from cylinder was extremely enhanced. Fu et al. (2010) numerically studied 3dimensional laminar channel flow with insertion of moving block. While block was moving, circulated flows were apparently generated at downstream. This phenomenon results in the heat transfer enhancement inside channel especially at the downstream region.

According to literature review, it can clearly be seen that flow, heat and structure have direct interaction. The vibration may enhance the heat transfer by disturbing the thermal and velocity boundary layer on heated surface. Previous studies focused on the conventional or large scale heat sinks. However, today the small scale heat sinks are widely used in electronics applications and nobody applies the vibration for small scale heat sinks. Therefore, in order to improve heat transfer performance, the vibration in the small scale heat sink is the challenging issue to be considered.

\subsection{Governing Equations and Numerical Method}

To focus on the fundamentals of flow and heat transfer of electronics heat sinks with different configurations, the two dimensional model is considered. Since the length scale of the fins is small and the Reynolds number is low, the flow is assumed to be laminar. The properties can be considered as constant because of the narrow temperature range. The continuity, momentum and energy equations for laminar flow can be listed as Equation 1-4:

$\frac{\partial \rho}{\partial t}+\rho\left(\frac{\partial u}{\partial x}+\frac{\partial v}{\partial y}\right)=0$ 


$$
\begin{aligned}
& \rho\left(\frac{\partial u}{\partial t}+u \frac{\partial u}{\partial x}+v \frac{\partial u}{\partial y}\right)=-\frac{\partial P}{\partial x}+\mu\left(\frac{\partial^{2} u}{\partial x^{2}}+\frac{\partial^{2} v}{\partial y^{2}}\right) \\
& \rho\left(\frac{\partial v}{\partial t}+u \frac{\partial v}{\partial x}+v \frac{\partial v}{\partial y}\right)=-\frac{\partial P}{\partial y}+\mu\left(\frac{\partial^{2} u}{\partial x^{2}}+\frac{\partial^{2} v}{\partial y^{2}}\right) \\
& \rho C_{p}\left(\frac{\partial T}{\partial t}+u \frac{\partial T}{\partial x}+v \frac{\partial T}{\partial y}\right)=k\left(\frac{\partial^{2} T}{\partial x^{2}}+\frac{\partial^{2} T}{\partial y^{2}}\right)
\end{aligned}
$$

where, $\mathrm{u}$ and $\mathrm{v}$ are the velocity in streamwise and spanwise direction. $\mathrm{P}, \mathrm{t}$ and $\mathrm{T}$ are the pressure, flowtime and temperature. The $\rho, C_{p}, k$ and $\mu$ which are the fluid properties are density, specific heat, thermal conductivity and dynamics viscosity, respectively. The commercial software package, fluent version 6.3.26, is used in this study. The governing equations are discretized by the finite volume method and the second order upwind scheme is adopted for spatial discretization of the convection terms. The segregated solver is used in the simulation and the SIMPLE algorithm is employed to couple the pressure and velocity (Patankar, 1980). The convergence criteria of iterative solution have been insured when the residual of all variables are less than specific values. The specified value is $10^{-5}$ for continuity, momentum and energy equations.

\subsection{Geometry and Boundary Condition}

The single square pin fin is presented in Fig. 1. The length and width of square pin fin are 0.001 and $0.001 \mathrm{~m}$ and the airflow is in $\mathrm{x}$ direction (streamwise direction).

For 2D baseline case, the square pin fin is selected to study and the typical domain with boundary conditions is illustrated in Fig. 2. Fin surface, upper and lower wall are defined as non-slip wall. The velocity inlet and pressure outlet conditions are used on region $\mathrm{AD}$ and $\mathrm{BC}$, respectively. Uniform velocity is employed for the flow inlet in the $\mathrm{x}$ direction. For heat transfer boundary condition, the constant temperature of $350 \mathrm{~K}$ is defined on fin surface and the upstream bulk temperature of inlet flow is set to $300 \mathrm{~K}$. The Reynolds number based on fin width of 100 is desired for the baseline case so that the averaged inlet velocity is $1.46 \mathrm{~m} / \mathrm{s}$. The working fluid is air and it is assumed to be ideal gas in order to calculate flow field and heat transfer.

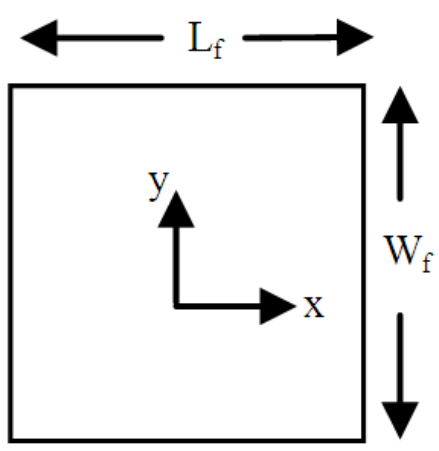

Fig. 1. Geometric scheme of the square pin fin

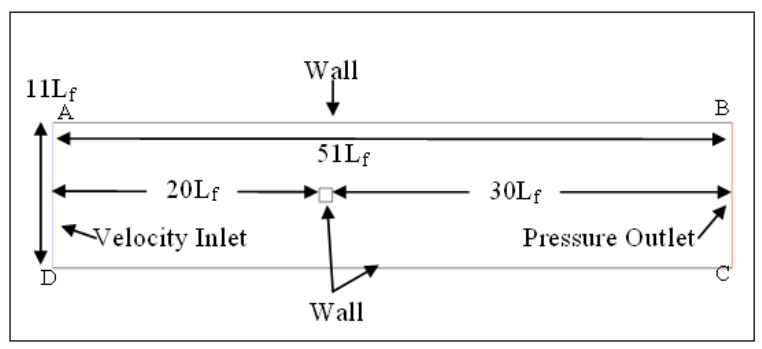

Fig. 2. Computational domain and boundary conditions for 2D square pin fin heat sink

For 2D square pin fin, the vibration in $\mathrm{x}$ direction is studied and the displacement equation is written as Equation 5:

$\delta=\mathrm{A} \sin (2 \pi \mathrm{ft})$

Particularly, nowadays effective frequency is generally performed well below $1,000 \mathrm{~Hz}$ (Bergles, 1998); therefore, the amplitude and frequency of 0.0002 $\mathrm{m}$ and $500 \mathrm{~Hz}$ are employed for the baseline case. The main parameters of $2 \mathrm{D}$ pin fin baseline case are summarized in Table 1.

\subsection{Grid Independence Study}

The 2D baseline square pin fin is meshed using structure and unstructured and it is presented in Fig. 3. At near pin fin surface, grid must be re-generated by Remeshing scheme (FD, 2006) while fin is moving so that the unstructured mesh appropriates. The other region, the non-uniform structure mesh is employed.

The square pin fin baseline case contains a total number of elements of 13,876 . The grid and timestep independence are studied for all cases and one of the example, which is $2 \mathrm{D}$ square pin fin with amplitude and frequency of $0.0003 \mathrm{~m}$ and 1,000 Hz, is shown in Table 2 . 


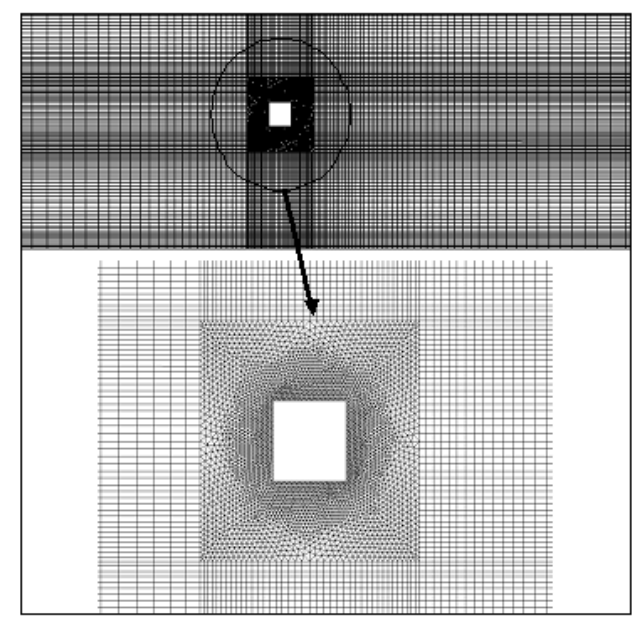

Fig. 3. Unstructured and structured non-uniform mesh for $2 \mathrm{D}$ pin fin baseline case

Table 1. Parameters of 2D square pin fin heat sink

\begin{tabular}{lr}
\hline Parameters & \\
\hline Pin fin shape & square \\
Fin length $\left(\mathrm{l}_{\mathrm{f}}\right)(\mathrm{m})$ & 0.0010 \\
Fin thickness $\left(\mathrm{W}_{\mathrm{f}}\right)(\mathrm{m})$ & 0.0010 \\
Temperature on the fin surface, $\mathrm{T}_{\mathrm{w}}(\mathrm{K})$ & 350.0000 \\
Inlet average bulk temperature, $\mathrm{T}_{\mathrm{a}}(\mathrm{K})$ & 300.0000 \\
Inlet average air velocity, $\mathrm{U}_{\mathrm{a}}(\mathrm{m} / \mathrm{s})$ & 1.4700 \\
Amplitude, $\mathrm{A}(\mathrm{m})$ & 0.0002 \\
Frequency, $\mathrm{F}(\mathrm{Hz})$ & 500.0000 \\
Vibration direction & $\mathrm{x}$ \\
\hline
\end{tabular}

Table 2. Overall performances with different grid systems for 2D square pin fin heat sink

\begin{tabular}{lll}
\hline Cases & Coarse grid & Fine grid \\
\hline Number of elements & 13,876 & 27,668 \\
Number of point per cycle & 80 & 80 \\
Timestep size (s) & $1.25 \times 10^{-5}$ & $1.25 \times 10^{-5}$ \\
Heat transfer rate (W) & 23.32 & 23.34 \\
Pressuredrop (Pa) & 31.81 & 31.57 \\
\hline
\end{tabular}

Table 3. Overall performances with different timestep for 2D square pin fin heat sink

\begin{tabular}{lll}
\hline Cases & Fine grid & Fine grid \\
\hline Number of elements & 27,668 & 27,668 \\
Number of point per cycle & 80 & 160 \\
Time step size (s) & $1.25 \times 10^{-5}$ & $2.65 \times 10^{-6}$ \\
Heat transfer rate $(\mathrm{W})$ & 23.34 & 23.59 \\
Pressuredrop $(\mathrm{Pa})$ & 31.57 & 30.22 \\
\hline
\end{tabular}

It can be seen that when the grid increases from 13,876 to 27,668 , the average heat transfer rate and maximum heat transfer rate change only 0.06 and $0.79 \%$, respectively.
Table 3 shows the result for timestep size independence study, the baseline case uses a timestep of $1.25 \times 10^{-5} \mathrm{~s}$ and it produces 80 points per cycle of vibration. When the timestep size is decreased to $6.25 \times 10^{-6} \mathrm{~s}$, it generates 160 points per cycles of vibration. It is observed that the percentages of difference are 1.07 and $4.42 \%$ for the average heat transfer rate and maximum heat transfer rate, respectively. Consequently, it is concluded that the heat transfer performance is not affected by grid and timestep size when the grid of 13,876 and timestep of $1.25 \times 10^{-5} \mathrm{~s}$ are applied.

\section{MATERIALS AND METHODS}

The two dimensional small scale heat sink is numerically studied and the commercial Computational Fluid Dynamics (CFD) software, Fluent, is used to determine heat transfer and flow field inside channel. The conventional personal computer with AMD Sempron LE-1640 and RAM 1024MB DDR2 is used to operate CFD software.

\section{RESULTS AND DISCUSSION}

\subsection{Baseline Case: Square Pin Fin with Frequency of 500, Amplitude of $0.0002 \mathrm{~m}$ and Reynolds number of 100}

This study mainly focuses on the situation when flow becomes steady. For 2D pin fin baseline case, the flow becomes steady state after passing 30 cycles of vibration. The streamlines and velocity vectors over square pin fin during steady state period at displacement of $0.0,0.0002$ and $-0.0002 \mathrm{~m}$ are presented in Fig. 4 respectively. In general, the flow field characteristic and its magnitude are quite reasonable. The flow begins separating at the corner near front end of pin fin on both bottom and top sides. The circulation zones visibly appear on top and bottom surfaces and they are clearly difference.

The total pressure distribution on pin fin at displacement of $0.0,0.0002$ and $-0.0002 \mathrm{~m}$ are illustrated in Fig. 5. The stagnation and low pressure regions can clearly be observed at front and rear sides. At displacement of $0.0002 \mathrm{~m}$, the stagnation and low pressure regions are biggest among all the locations. This effect makes the pressure drop in the $\mathrm{x}$ direction extremely high when pin fin stops at this location.

Figure 6 presents the pressure drop in the $\mathrm{x}$ direction versus vibration cycle and timestep of baseline case. It is seen that the pressure drop fluctuates and it is clearly related to the vibration cycle. 
Suabsakul Gururatana and Xianchang Li / American Journal of Applied Sciences 10 (8): 801-809, 2013
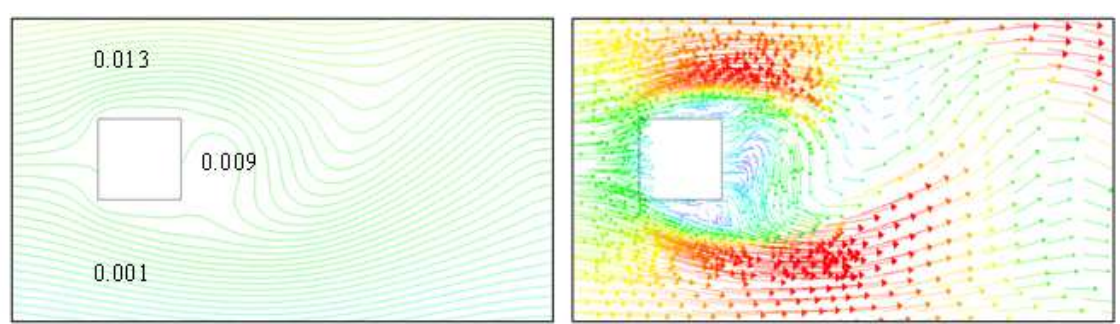

(a)
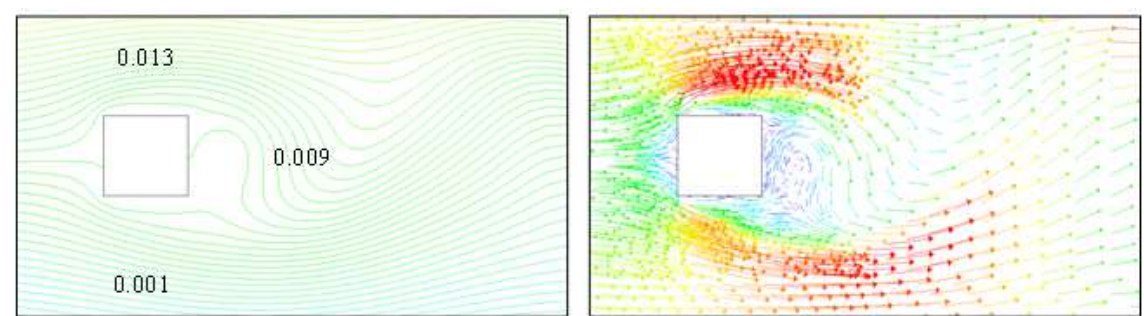

(b)
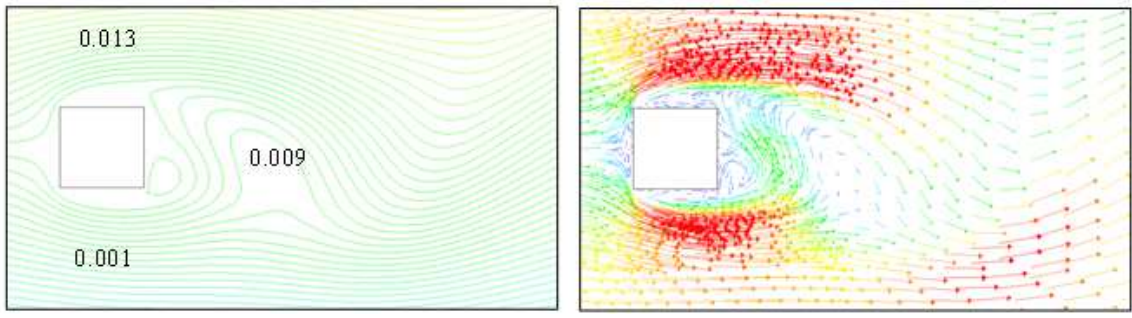

(c)

Fig. 4. The Streamlines and velocity vectors for $2 \mathrm{D}$ pin fin baseline case at displacement of (a) $0.0 \mathrm{~m}$, (b) $0.0002 \mathrm{~m}$ and (c) $-0.0002 \mathrm{~m}$

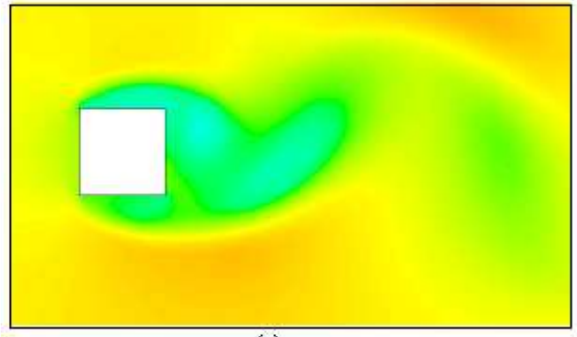

(a)

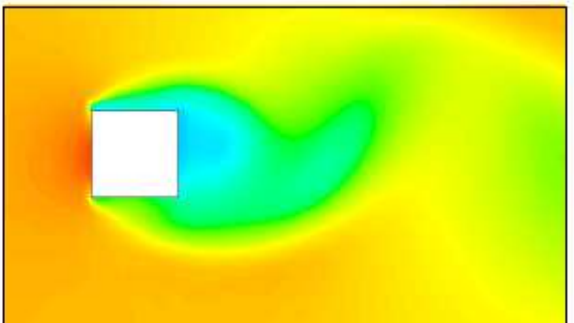

(b)

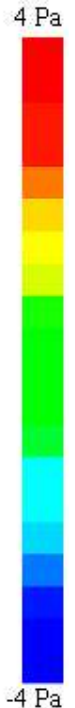

(c)

Fig. 5. Total pressure for baseline case at displacement of (a) $0.0 \mathrm{~m}$, (b) $0.0002 \mathrm{~m}$ and (c) $-0.0002 \mathrm{~m}$ 
Suabsakul Gururatana and Xianchang Li / American Journal of Applied Sciences 10 (8): 801-809, 2013

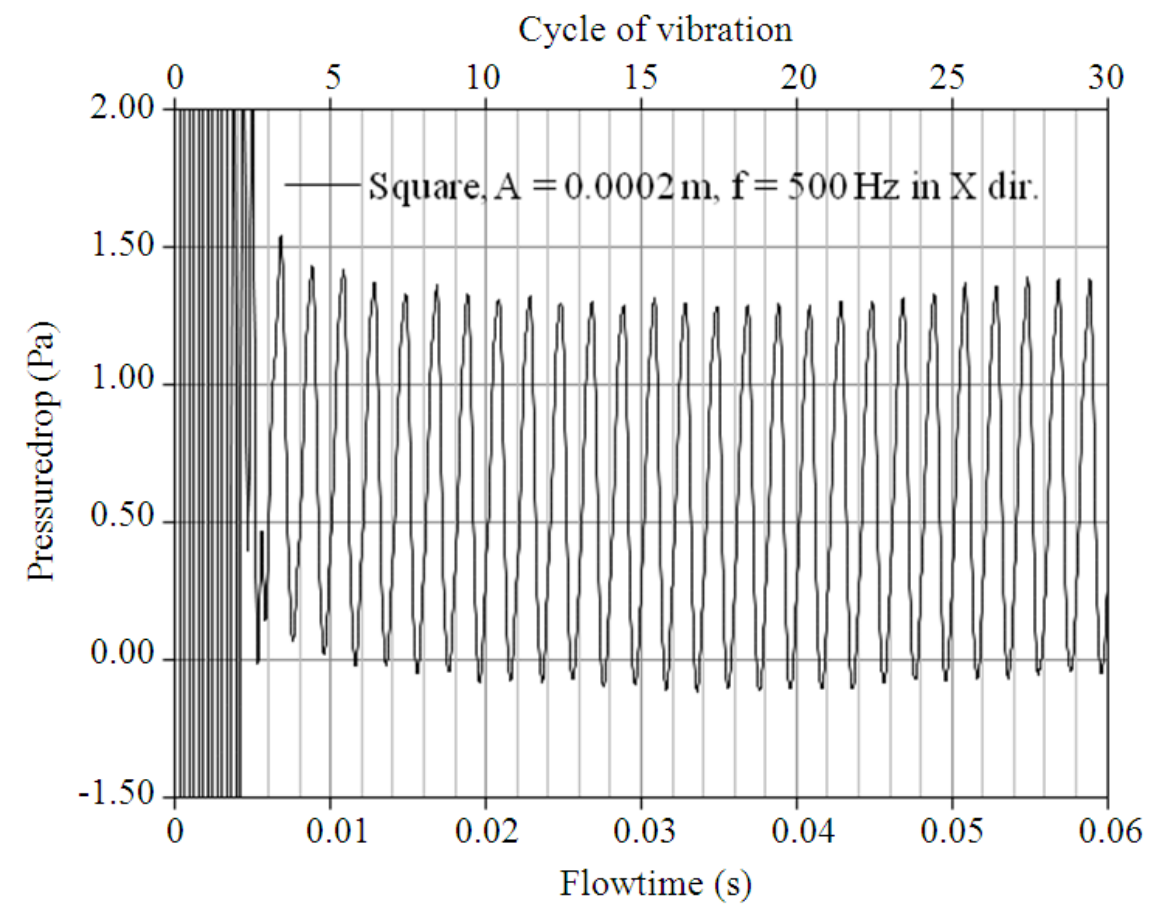

Fig. 6. Pressure drop in $\mathrm{X}$ direction for 2D pin fin baseline case

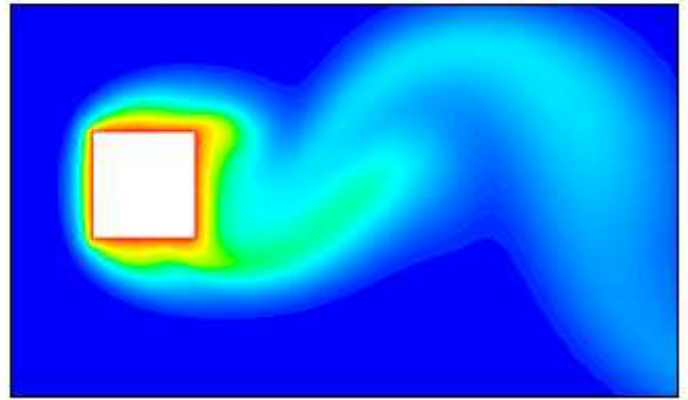

(a)

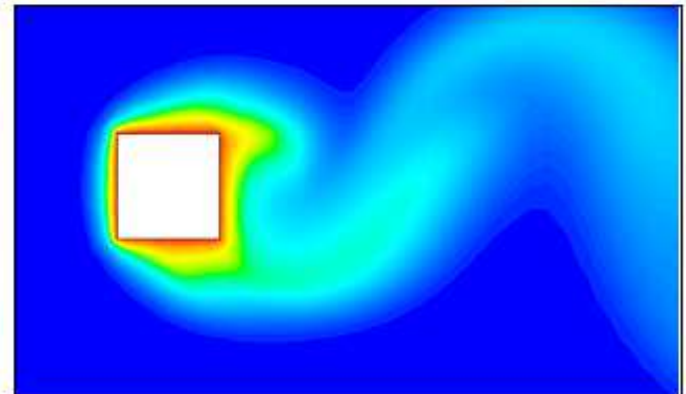

(b)
$350 \mathrm{~K}$

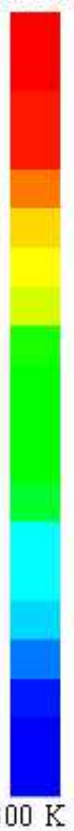

(c)

Fig. 7. Temperature contour for $2 \mathrm{D}$ pin fin at displacement of (a) $0.0 \mathrm{~m}$, (b) $0.0002 \mathrm{~m}$ and (c) $-0.0002 \mathrm{~m}$ 


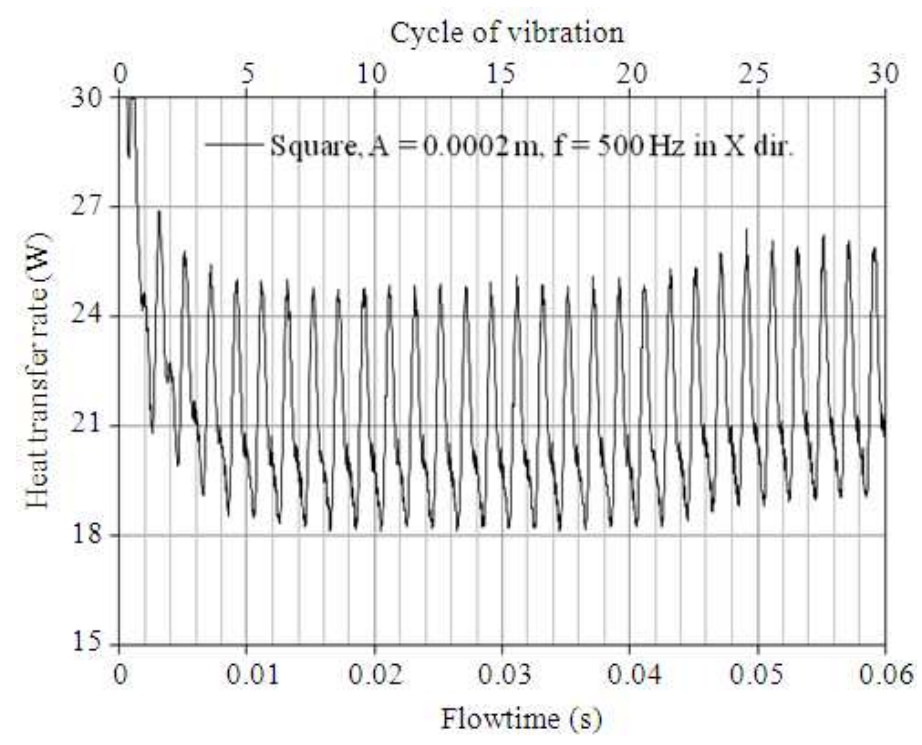

Fig. 8. Heat transfer rate for $2 \mathrm{D}$ pin fin baseline case

According to pressure distribution in Fig. 5, when pin fin moves to displacement of $-0.0002 \mathrm{~m}$, pressure drop begins reduced quickly. Then, the pressure drop rapidly rises again when pin fin goes back into displacement of $0.0002 \mathrm{~m}$.

The temperature distribution over the pin fin at displacement of $0.0,0.0002$ and-0.0002 $\mathrm{m}$ are shown Fig. 7. The development of the thermal boundary layer along fin both top and bottom surface can be observed. However, both boundary layers are obviously not smooth and similar because while the pin fin is moving, thermal boundary layer is disturbed by wakes behind the pin fin.

The heat transfer rate from pin fin versus timestep and vibration cycle is presented in Fig. 8. The heat transfer rate is calculated by total surface heat flux and pin fin surface area; it can be written as Equation 6:

$$
\mathrm{Q}=\mathrm{q}^{\prime \prime} \mathrm{A}_{\mathrm{S}}
$$

Where:

$\mathrm{Q}=$ Heat transfer rate

$\mathrm{q}^{\prime \prime}=$ Heat flux

$\mathrm{A}_{\mathrm{s}}=$ Pin fin surface area

The trend of heat transfer is periodic pattern and also related to vibration cycle and it becomes steady state when passing 30 cycles of vibration. The maximum and minimum heat transfer rates are $26.50 \mathrm{~W}$ and $19.81 \mathrm{~W}$.

\subsection{Effect of Frequency on 2D Square Pin Fin Heat Sink}

The effect of frequency on square pin fin with amplitude $0.0002 \mathrm{~m}$ is investigated and the maximum heat transfer rate is shown in Fig. 9 and the overall performance is summarized in Table 4. It can be seen that at low frequency period ( $<<500 \mathrm{~Hz}$ ) the heat transfer increases as the frequency goes higher. During frequency of 500 to $1,000 \mathrm{~Hz}$, the heat transfer slightly raises.

Next, the maximum pressure drop in the $\mathrm{x}$ direction versus frequency is illustrated in Fig. 10. The pressure drop significantly becomes large while frequency increases and the relationship between pressure drop and frequency are clearly not linear.

In order to compare the heat transfer with different frequencies, the heat transfer enhancement performance is used. The heat transfer enhancement performance (HTEP) can be written as Equation 7:

$\mathrm{HTEP}=\left(\frac{\mathrm{Q}_{\mathrm{V}}}{\mathrm{Q}_{\mathrm{NV}}}\right) /\left(\frac{\Delta \mathrm{P}_{\mathrm{V}}}{\Delta \mathrm{P}_{\mathrm{NV}}}\right)^{\frac{1}{3}}$

Where:

$\Delta \mathrm{P}_{\mathrm{V}}=$ Pressure drop of vibrating fin

$\Delta \mathrm{P}_{\mathrm{NV}}=$ Pressure drop of non-vibrating fin

$\mathrm{Q}_{\mathrm{V}} \quad=$ Heat transfer rate of vibrating fin

$\mathrm{Q}_{\mathrm{NV}}=$ Heat transfer rate of non-vibrating fin 


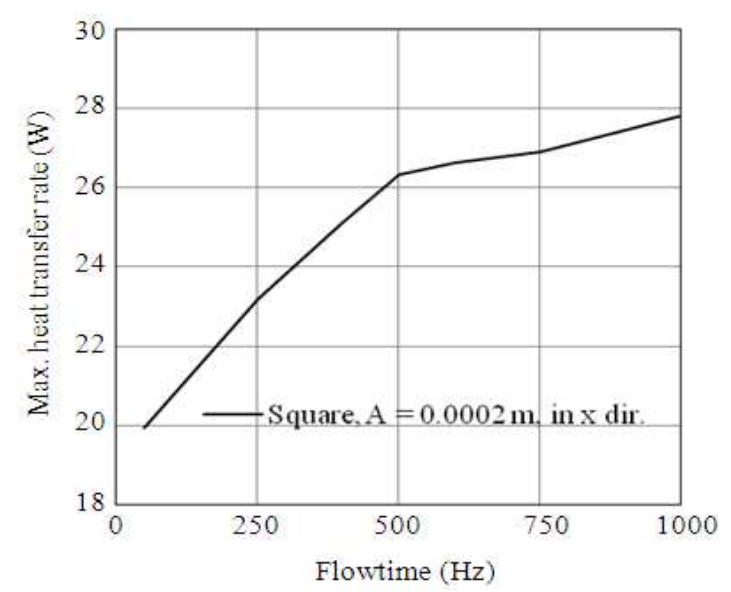

Fig. 9. Effect of frequency on maximum heat transfer for 2D square pin fin

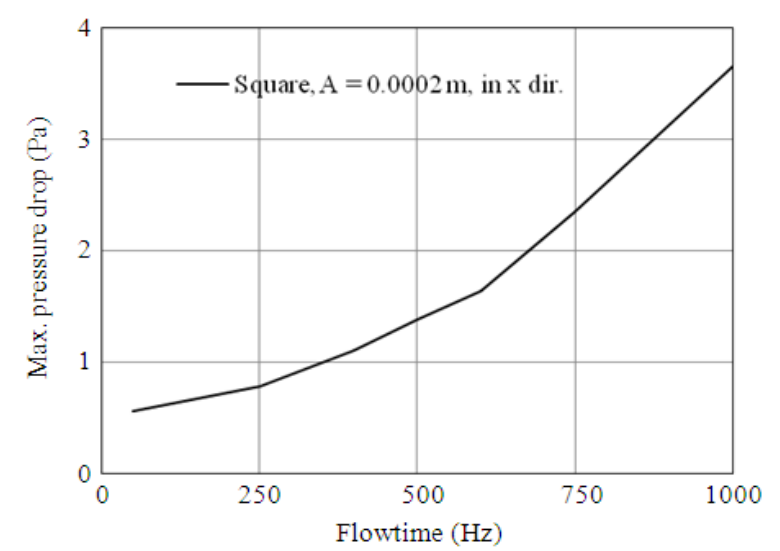

Fig. 10. Effect of frequency on maximum Pressure drop for 2D square pin fin

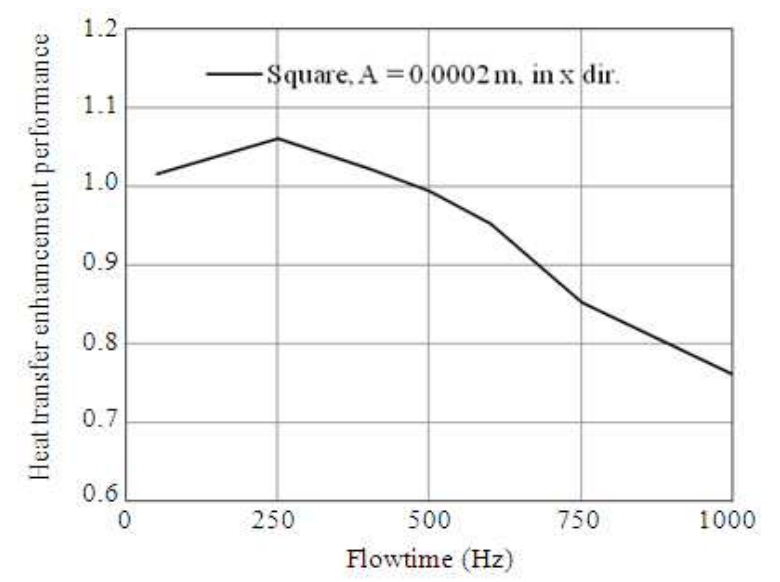

Fig. 11. Effect of frequency on heat transfer enhancement performance for $2 \mathrm{D}$ square pin fin
Table 4. Overall performances for 2D square pin fin heat sink with different frequencies

\begin{tabular}{lrlll}
\hline Amp. $(\mathrm{m})$ & $\mathrm{f}(\mathrm{Hz})$ & Max. Q $(\mathrm{W})$ & Max. $\Delta \mathrm{P}(\mathrm{Pa})$ & HTEP \\
\hline 0.0002 & 50 & 19.96 & 0.58 & 1.02 \\
0.0002 & 250 & 23.18 & 0.78 & 1.06 \\
0.0002 & 400 & 25.13 & 1.11 & 1.02 \\
0.0002 & 500 & 26.35 & 1.39 & 0.99 \\
0.0002 & 600 & 26.65 & 1.64 & 0.95 \\
0.0002 & 750 & 26.91 & 2.35 & 0.85 \\
0.0002 & 1,000 & 27.83 & 3.66 & 0.76 \\
\hline
\end{tabular}

The heat transfer enhancement performance for square pin fin with amplitude $0.0002 \mathrm{~m}$ versus frequencies is presented in Fig. 11 and the overall performance is summarized in Table 4. The case of vibrating pin fin is compared with non-vibrating pin fin, which has maximum heat transfer and maximum pressure drop of $19.33 \mathrm{~W}$ and $0.54 \mathrm{~Pa}$, respectively. It would be seen that performance raises until frequency of $250 \mathrm{~Hz}$. Afterward, it slightly decreases when frequency increases. Note that the performance begins to drop down because the range of high frequencies the heat transfer changes only slightly, but pressure drop increases quickly. The decrease of performance can be caused by significant pressure drop

\subsection{Validation of Numerical Results}

The commercial software package has been validated at least for problems as simple as in this study. Further validation is performed in this study for the numerical procedures and settings. Since there is no test data found in literature, a simplified model for a laminar flow and heat transfer inside 2D channel is considered. This simplified model is simulated at Reynolds number of 1,000 based on the hydraulic diameter. The wall and inlet air temperature are 320 and $300 \mathrm{~K}$, respectively. The theoretical Nusselt number is 7.54 (Incropera et al., 2006). The Nusselt number from numerical result is 7.48 at Reynolds number of 1,000 . It can be seen that the numerical result is different from theoretical by only $2.7 \%$. Thus, it is concluded that numerical results in this study are consistent with the literature and experimental values.

\section{CONCLUSION}

The small-scale pin-fin heat sinks with vibration effect are investigated. The study focuses on parametric variations and the conclusion of this section can be listed as: 
- The heat transfer rate and pressure drop for $2 \mathrm{D}$ square pin fins heat sinks presents periodic pattern related to cycle of vibration

- For 2D pin fins heat sinks, maximum heat transfer rate increases when the frequency is less than $500 \mathrm{~Hz}$. However, if frequency is greater than $500 \mathrm{~Hz}$, the maximum heat transfer rate insignificantly increases

- Maximum pressure drop significantly rises with frequency

- Heat transfer enhancement performance for 2D pin fin heat sinks increases until certain frequency; afterward it rapidly decreases with frequency

\section{ACKNOWLEDGMENT}

This study is achieved with the supports from the Faculty of Engineering at $\mathrm{Si}$ Racha, Kasetsart University Si Racha campus, Mechanical Engineering Department, Kasetsart University and Lamar University, USA.

\section{REFERENCES}

Bergles, A.E., 1998. Techniques to Enhance Heat Transfer. In: Handbook of Heat Transfer. Rohsenow, W.M., J.P. Hartnett and Y.I. Cho (Eds.), McGrawHill, New York, ISBN-10: 0070535558.

FD, 2006. Version 6.3.23. Fluent Inc.

Forbes, RE., C.T. Carley and C.J. Bell, 1970. Vibration effects on convection heat transfer in enclosures. J. Heat Transfer, 92: 429-438. DOI: 10.1115/1.3449681

Fu, W.S. and B.H. Tong, 2002. Numerical investigation of heat transfer from heated oscillating cylinder in a cross flow. Int. J. Heat Mass Transfer, 45: 30333043. DOI: 10.1016/S0017-9310(02)00016-9

Fu, W.S. and S.J. Yang, 2001b. A new model for heat transfer of fins swinging back and forth in flow. Int. J. Heat Mass Transfer, 44: 1678-1679. DOI: 10.1016/S0017-9310(00)00220-9

$\mathrm{Fu}$, W.S. and S.T. Yang, 2001a. Heat transfer induced by a body moving in opposition to a flowing fluid. Int. J. Heat Mass Transfer, 44: 89-98. DOI: 10.1016/S0017-9310(00)00091-0

Fu, W.S., J.C. Huang and C.G. Li, 2010. Enhancement of forced convection heat transfer in a three dimensional laminar channel flow with insertion of a moving block. Int. J. Heat Mass Transfer, 53: 3887-3897. DOI: $10.1016 /$ j.ijheatmasstransfer.2010.05.007
Fu, W.S., K.N. Wang and W.W. Ke, 2001. An investigation of a block moving back and forth on a heat plate under a slot jet. Int. J. Heat Mass Transfer, 44: 2621-2631. DOI: 10.1016/S00179310(00)00305-7

Hui, Z.J. and Y.C. Xin, 2008. Design and simulation of the CPU fan and heat sinks. IEEE Trans. Components Packag. Technol., 31: 890-903. DOI: 10.1109/TCAPT.2008.2006188

Incropera, F.P., D.P. DeWitt, T.L. Bergman and A.S. Lavine, 2006. Introduction to Heat Transfer. 5th Edn., Wiley, Hoboken, ISBN-10: 0471457272, pp: 912.

Ji, T.H., S.Y. Kim and J.M. Hyun, 2008. Experiments on heat transfer enhancement from a heated square cylinder in a pulsating channel flow. Int. J. Heat Mass Transfer, 51: 1130-1138. DOI: 10.1016/j.ijheatmasstransfer.2007.04.015

Li, C. and R.A. Wirtz, 2005. Development of a high performance heat sink based on screen-fin technology. IEEE Trans. Components Packag. Technol., 28: 80-87. DOI: 10.1109/TCAPT.2004.843171

Ozturk, E. and I. Tari, 2008. Forced air cooling of CPUs with heat sinks: A numerical study. IEEE Trans. Components Packag. Technol., 31: 650-660. DOI: 10.1109/TCAPT.2008.2001840

Patankar, S.V., 1980. Numerical Heat Transfer and Fluid Flow. 1st Edn., Hemisphere Pub. Corp., New York, ISBN-10: 0070487405, pp: 197.

Pottebaum, T.S. and M. Gharib, 2006. Using oscillations to enhance heat transfer for a circular cylinder. Int. J. Heat Mass Transfer, 49: 3190-3210. DOI: 10.1016/j.ijheatmasstransfer.2006.01.037

Takada, J., Y. Kimura, T. Ogushi, M. Fujii and M. Kohara et al., 1990. Development of a new aircooling heat sink for a high density computer system. Proceedings of the Electronic Components and Technology Conference, May 20-23, pp: 534539. DOI: 10.1109/ECTC.1990.122239

Tuckerman, D.B. and R.F.Q. Pease, 1981. Highperformance heat sinking for VLSI. Electr. Device Lett., 2: 126-129. DOI: 10.1109/EDL.1981.25367 